\title{
IR absorption spectra in the region of stretching and deformation vibrations of hydrogen bond in pure and alloyed single crystals of $\mathrm{LiNbO}_{3}$
}

\author{
N.N. Novikova ${ }^{1}$, V.A. Yakovlev ${ }^{1}$, and N.V. Sidorov ${ }^{2, *}$ \\ ${ }^{1}$ Institute for Spectroscopy RAS, 108840 Moscow, Troitsk, Russia \\ ${ }^{2}$ I.V.Tananaev Institute of Chemistry and Technology of Rare Elements and Mineral Raw Materials, \\ Kola Science Center RAS, 184209 Apatity, Russia
}

\begin{abstract}
We have measured infrared absorption spectra of the stretching and bending vibrations of the hydrogen bond of pure and alloy additives $\mathrm{Me}$ $(\mathrm{Me}=\mathrm{Mg}, \mathrm{Zn})$ single crystals of lithium niobate $\left(\mathrm{LiNbO}_{3}\right)$ grown using various technologies. Preliminary studies of the spectra showed that the frequency of stretching vibrations in the IR spectra of single-crystal samples obtained from the homogeneously doped charge differ significantly (more than $50 \mathrm{~cm}^{-1}$ ). However, no difference in the IR spectra of single crystals obtained using other doping techniques, we have found. It is assumed that the observed differences in the absorption spectra of single crystals due to the different character of the formation of hydrogen bonds in the preparation of precursors $\mathrm{Nb}_{2} \mathrm{O}_{5}$ : Me.
\end{abstract}

The infrared absorption spectra were studied in the polarized radiation in the region of stretching and deformation vibrations of hydrogen bonds for more than 60 nominally pure and alloyed in a wide range of concentrations of alloying elements $\mathrm{Me}(\mathrm{Me}=\mathrm{Mg}, \mathrm{Zn})$ single crystals of lithium niobate $\left(\mathrm{LiNbO}_{3}\right)$, grown by various techniques. Four techniques of doping were used to prepare these crystals:

1. Homogeneous doping is the synthesis of granulated mixture with a high bulk density is produced using a homogeneous solid $\mathrm{Nb}_{2} \mathrm{O}_{5}$ :Me precursors, obtained by homogeneous doping of $\mathrm{Me}$, recovered at the stage of extraction separation $\mathrm{Nb}_{2} \mathrm{O}_{5}$. This method of doping is based on sorption of respective cations of alloying of high-purity niobium hydroxide. At the same homogeneously doped solid precursor $\mathrm{Nb}_{2} \mathrm{O}_{5}: \mathrm{Me}$, in turn, was obtained in two ways: by separation from reextract, obtained by extrakt processing or fluoride-sulfuric (method I) or fluoride-hydrochloric acid solutions (method II) from processing rare metal raw materials and wastes of lithium niobate.

2. Direct addition - direct addition of the appropriate alloying of the Me oxide into the granular mixture with a high bulk density before fusion of the crucible.

3. Addition before fusing the crucible into the granular mixture with a high bulk density of the synthesized $\mathrm{LiNbO}_{3}$-based special alloys, enriched in alloying elements $\mathrm{Me}$.

\footnotetext{
* Corresponding author: sidorov@chemy.kolasc.net.ru
} 
4. The use of granulated furnace charge with high bulk density, synthesized from a homogenous mixture of niobium pentoxide, the oxide of alloying element Me and lithium carbonate.

All the single crystals both nominally pure and doped, were grown in air atmosphere by Czochralski method using the same methodology on the "Crystal-2". Crystalline samples for studies had the shape of rectangular parallelepipeds with dimensions of $\sim 7 \times 6 \times 5 \mathrm{~mm}^{3}$ with edges coinciding in direction with crystal axes $\mathrm{X}, \mathrm{Y}, \mathrm{Z}$, where the $\mathrm{Z}$ axis is the polar axis of the crystal. The faces of the parallelepipeds were carefully polished. Preliminary studies of the IR absorption spectra of single crystals obtained by different techniques showed, that in the region of stretching and deformation vibrations of hydrogen bonds there are significant differences in the frequencies of the oscillations. So the frequency of stretching vibrations in the IR spectra of single crystal samples obtained from a homogeneous alloy mixture, in turn obtained using $\mathrm{Nb}_{2} \mathrm{O}_{5}$ : Me precursors by method I and method II, are significantly (more than $50 \mathrm{~cm}^{-1}$ ) different. However, no differences in the IR spectra of single crystals obtained using other methods of alloying, we did not found.

The detected differences in the IR absorption spectra of single crystal samples is, in our opinion, due to the different nature of the hydrogen bonds formed in the preparation of precursors for $\mathrm{Nb}_{2} \mathrm{O}_{5}$ : Me in fluoride-sulfuric acid (method I) or fluoride-hydrochloric acid solutions (method II). Study of the nature of the hydrogen bonds formed in these two types of solutions is a matter of further special study.

\section{Reference}

1. M.N. Palatnikov, I.V. Biriukjva, O.V. Makarova, N.V. Sidorov, N.A. Tepliakova, S.M. Masloboeva, V.V. Efremov, Journal Perspektivnye materialy 1, 5 (2016) (in Russian) 